\title{
The Impact of Covid-19 on Research Process Case of Study Master 2 EFL Students at The University of Mohammed Seddik Ben Yahia, Jijel- Algeria
}

\author{
Aïcha Boufenchoucha ${ }^{1 *}$, and Oktiva Herry Chandra ${ }^{2}$ \\ ${ }^{1}$ Department of Linguistics, Faculty of Humanities, Diponegoro University, Semarang - Indonesia \\ ${ }^{2}$ Department of Linguistics, Faculty of Humanities, Diponegoro University, Semarang - Indonesia
}

\begin{abstract}
This study explained how English Master-2 students at JijelUniversity dealt with problems and impacts when writing their dissertations and research papers during the Corona virus pandemic. The following research questions are identified as: what obstacles and effects has the Covid-19 crisis had on the research papers writing process of EFL Master Students, what coping strategies have teachers, students, and what administration used to avoid anxiety and ensure academic productivity? A questionnaire was administered to 25 Students. This inquiry is significant because, it documents the unique experience of research writing under Covid-19 pandemic and seeks to unravel the challenges and impacts of this situation on the graduating students to sensitize educational authorities and teachers about them in the view of averting them in the future and ensuring a better preparation for such eventualities in this unstable world. The results showed that Covid-19 pandemic had negative effects on the process of written a research papers at university, Students lacked the accessibility of some sources, and they had to carry out their study on an online platform and limit the sample size to fewer students, and there was a significant disruption in the provision of the needed atmosphere to do an experimental study.
\end{abstract}

\section{Introduction}

The Coronavirus is a never-ending virus. With the continuing closing of universities and public libraries, many EFL students in the Algerian Universities who are about to graduate are befuddled. They are supposed to schedule their notes and deliver them on time, but they lack the necessary references and tools. The suggested thesis titles were presented to the second-year Master's students at the University of Mohammed Seddik Ben Yahia, Jijel. EFL Master 2 students had no idea that the Covid-19 pandemic would sweep the globe, and that the university's doors, as well as those universities and "semi-universities" libraries, would be barred, and that transportation would be suspended. Students would be forced to connect

*Corresponding author: aichanet2015@gmail.com 
with their supervisors by e-mail and social networks. After the quarantine's implementation, students have made little gains with their researchers. The research methodologies probably play a major role in the extent to which persons experience the impact of COVID-19. Some researchers could have been more quickly adapted to pandemic problems because of the variability of psychological techniques. However, the generalizability of data gathered in these exceptional circumstances could be a problem even for those who can continue their research (Lourenco \& Tasimi, 2020; Wolkewitz and Puljak, 2020).

The Chronicle of Higher Education, a specialist periodical magazine that disseminates news about higher education in universities and colleges throughout the United States, published NF Foley's article [1] 'Don't Forget about Graduate Students'. According to the scholar, who has a $\mathrm{PhD}$ and a thesis pending at Harvard University, the effect of Covid-19 is so significant that many $\mathrm{PhD}$ students are leaving their thesis projects pending or unfinished, so they would not be able to "graduate within five or six years." That implies they failed their studies and their dreams were ruined. It is anticipated that specific programs will be restored and continued in the immediate future, most certainly with significant changes. Many more, though, would be unable to take effect owing to the current coexistence dynamics that are developing. There is no thesis without study, and there is no graduation without a thesis. This hurts the life plans of thousands of graduate students who plan to graduate in 2020 or 2021 and maybe have essential jobs in the future. Various researchers, students and academics have been affected by the COVID-19 epidemic. Since higher education institutions have limited personal activities, there have been disruptions to research and training. As a result, many graduates encounter additional obstacles (Chenneville and Schwartz-Mette, 2020; Thompson, 2020).

A 'UNUSUL' FUTURE: How long would this Covid-19 last? Nobody knows anything about it. There are various predictions, ranging from optimists who expect a quick return to the same old world to pessimists; as a result, they signify a profound shift in our standard way of life. According to Susan Hayter [2], from the Global Labor University Online Academy, in an interview with the United Nations newsletter (UN News), and published on May 27 under the title 'Business as unusual': How Covid-19 could change the future of work, points out that is well known to everyone, that the pandemic forced millions of people across the world to work remotely, virtually. However, she wonders, could this unusual situation change the future of work? Is this the university's future? As the abolition of regulations proceeds steadily, enterprise or distance education will keep up, but normalization will take years.

SCENARIOS POST-PANDEMIC: How much more time will the post-pandemic situation rob us of, under which limits will inevitably be enforced that would limit regular life? What would it be like at university? What is on the way? Just a crystal ball might tell us, but we may speculate. The essay post-pandemic plan for US Higher Education (Harvard Business Review, June 2020) by Professors Vijay Govindarajan and Anup Srivastava [3] assumes the current educational policy of American universities might be. They begin with the fact that two of the pandemic's positive results kept people at home and then propose three models of what post-pandemic university education might be, based on their projections: 1) Residential Model of Augmented Immersion. The traditional university, which consists of classroom and laboratory instruction, is supplemented by immersive technologies at home. In other words, simulated worlds mimic actual classrooms and enable students to immerse themselves in learning from the comfort of their own homes. It necessitates sophisticated technologies. 2) The Hybrid Model Since the residential university is costly; the new scenario provides university administrators with the ability to investigate a hybrid between face-to-face and online education. As well as the usage of the university's extensive resources for online instruction. The virtual scheme is the same as what is now in 
operation. 3) Fully online model. The writers believe that online schooling would be less expensive than face-to-face education.

COMPUTERS, SMARTPHONES, LAPTOPS: What about the student team, though? And what about the teachers' group, since they operate from home? With the Covid-19 crisis, it has been observed, at least in Mexico, that the majority of university's students do not have suitable equipment since the tool they use is too old, and they cannot upgrade the software that is needed. Furthermore, several students are just familiar with their mobile phones. Few people own a tablet computer. When preparing and developing a post-pandemic curriculum.

ON THE EDGE OF POST-PANDEMIC: We have not yet entered the post-pandemic. The effects of the quarantine continue to manifest themselves everywhere. People continue to fall ill and die. The economic, social, political, religious, and other impacts continue to occur. And within the framework of this setting, unusual violence is breaking out that threatens to spread in the countries. Like almost all institutions and workplaces (factories and businesses), universities were forced to close or operate partially and remotely. They still have not recovered from the scare and must already have figured out how to work the next school year. There is no doubt that this historical episode of coronavirus-19 will leave its mark and have lasting effects on universities. The challenge will be to juggle so many things: confinement, work, living together at home, studying, and not losing your judgment and physical health. According to Stephen M. Walt [4]: “Covid-19 will create a less open, less prosperous and less free world". Bogle said that the epidemic has dramatically altered the world of research and academia and that many of it will stay with us. Although David \& Stegle think that we have not been aware for some time of the long-term impact of the SARSCoV-2 virus outbreak, many of us have already started to sense the impacts.

The following study questions were given to explain better how the Covid-19 pandemic has affected Master 2 EFL students and their problems when doing their different research papers. The author presents the following questions: What impacts and effects has the Covid19 crisis had on the research paper writing process of EFL Master 2 Students, and what strategies have been used to avoid anxiety and ensure academic productivity?

\section{Method}

This study uses a qualitative research tool to answer the research questions and check the validity of the above-stated assumption. A questionnaire was administered to twenty-five (25) Master 2 EFL students at Mohammed Seddik Ben Yahia-Jijel University. A questionnaire is one of the most valuable testing tools; it consists of a set of questions. According to Nunan (1992) [5], a questionnaire is a research tool that is usually in written form and consists of open/closed questions (p.134). The students' questionnaire contains ten questions for twenty-five master's 02 students. The questionnaire was held online using Google form because it was the only option to reach the teachers and students during the current situation of the Covid-19 pandemic.

\section{Results}

\subsection{Analysis of the Students' Questionnaire:}

This part analyzes the details gathered from the students' questionnaire and the results of each analysis regarding the questions of the questionnaire. 


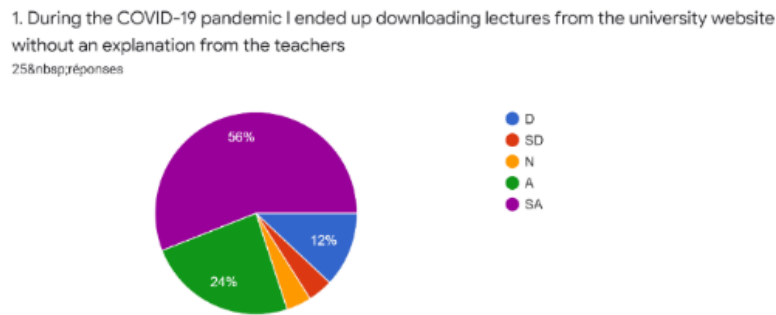

Fig. 1. During the Covid-19 pandemic, I ended up downloading lectures from the university website without and explanation from the teachers.

The first question seeks to ascertain if learners during the covid-19 ended up downloading lectures from the university website without explanation from their university's teachers. This question aims to determine whether students were aware of the modern method of receiving lectures during the Covid-19 pandemic. As seen in the graph above, (56\%) of students out of $(100 \%)$ strongly agree that they downloaded only the lectures from the university website and did not have teachers' explanations regarding the lessons during the pandemic, although (22\%) agree. Just (12\%) reported that they received the lessons with the teacher's explanation. The results show that when participants download the lessons online, they are aware of the significance of the teacher's explanation.

2. I am currently working on my dissertation only from home without going to university 258nbsp:réponses

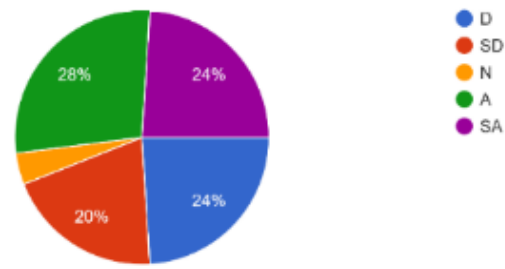

Fig. 2. I am currently working on my dissertation only from home without going to university.

The second question was intended to diagnose Master two students who do not attend university if they work solely from home on their dissertations. According to the answers, $(28 \%)$ agree, while (24\%) strongly agree that they work from home only without going to universities. Another (24\%) of the students disagree, while another (20\%) strongly disagree. This means that more than half of the participants claim to only work from home, while the rest do not. Based on the data collected, it is clear that two groups of students are conducting their studies in different ways.

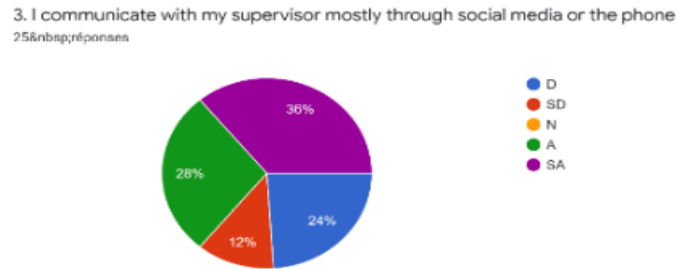

Fig. 3. I communicate with my supervisor mostly through social media or the phone. 
The third question is intended to elicit information from participants about whether students interact with their supervisors primarily through social media and phone calls. $(36 \%)$ of students stated that they strongly agree, implying that they still use this method to communicate with their superiors, while (28\%) said that they agree. On the other hand, $(24 \%)$ disagree, but there are other reasons they use this way with their teachers for communication, and $(12 \%)$ strongly disagree. As a result, since the majority of the learners involved seem to use only social media and phone to communicate with their supervisors during the Covid-19 pandemic, we anticipate that they would not receive as much input as they would if they met in person.

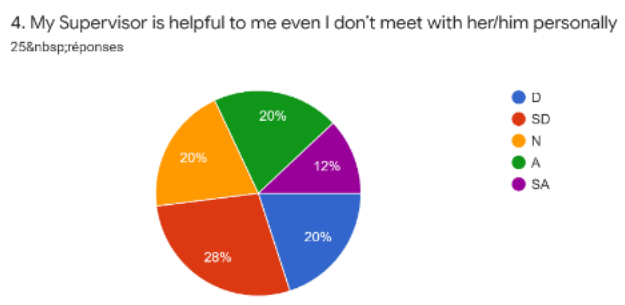

Fig. 4. My supervisor is helpful to me even I do not meet with her/him personally.

The participants' responses show that (28\%) strongly deny that their supervisor is helpful to them even though they do not meet in person. However, $(20 \%)$ of those surveyed students said they agreed. Other respondents $(20 \%)$ said that they were neutral. Others $(20 \%)$ believe that their supervisor is supportive even though they do not meet with them in person. Overall, we can see that most students need to meet their superiors in person so that they can be more supportive.

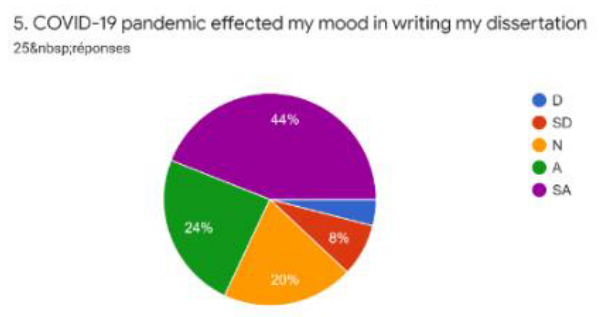

Fig. 5. COVID-19 pandemic effected my mood in writing my dissertation.

As seen in the graph above, (44\%) of respondents strongly agreed that the Covid-19 pandemic affected their mood when writing their dissertation. (24\%) of respondents said they agree. Furthermore, $(20 \%)$ reported Neutral. And only $(8 \%)$ of students said that they disagreed. To summarize, most students admitted that the Covid-19 pandemic had a strong impact on their mood on writing their dissertation. 


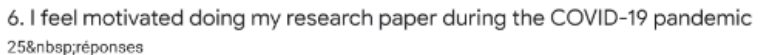

25\&nbsp;réponses

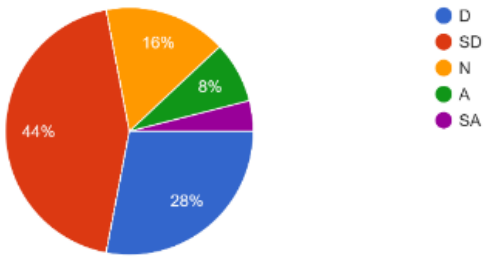

Fig. 6. I feel motivated doing my research paper during the COVID-19.

As shown in the graph above. (44\%) of students strongly disagree about whether they are motivated to write their research paper during the covid-19 pandemic. (28\%) stated that they oppose. (16\%) assumed they were neutral. However, only $8 \%$ of those polled said they agreed. According to the findings, most of the sampled population did not feel motivated to complete their research paper during the Covid-19 pandemic. As a result, we anticipate that the student's responses to the following question will be relevant.

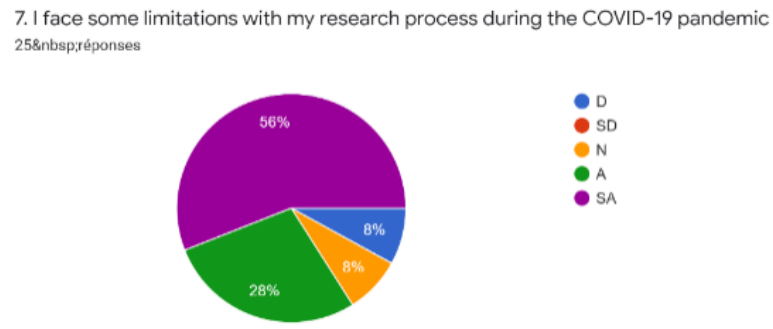

Fig. 7. I face some limitations with my research process during the COVID-19 Pandemic.

The figure above shows that 25 students $(100 \%)$, (58\%) strongly agree that they face certain limitations with their study process during the Covid-19 pandemic. In contrast, the remaining (28\%) agree and $(8 \%)$ are neutral, and the remaining $8 \%$ disagree. Overall, the Covid-19 pandemic is making it difficult for most students to complete their studies. One of the reasons is that students lack the accessibility to sources like books and articles.

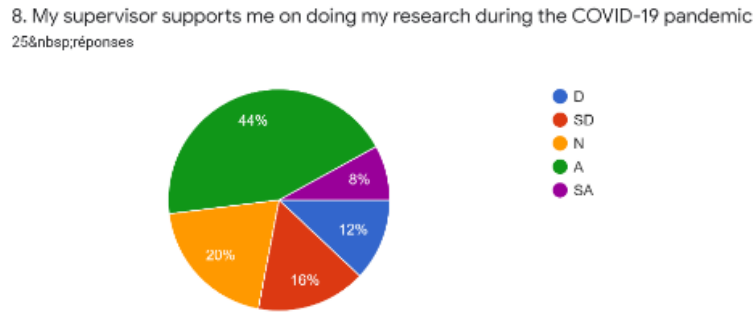

Fig. 8. My supervisor supports me on doing my research during the COVID-19 pandemic.

During the Covid-19 pandemic, $44 \%$ of students believe their supervisors are assisting them in progressing their research papers. $(20 \%)$ claimed that they were neutral. $(16 \%)$ of students indicated that they strongly disagree. However, $12 \%$ of those polled said that they 
disagreed. (8\%) firmly believe that their supervisors are assisting them in conducting their studies. Overall, we can conclude that most students acknowledge that their supervisors assist them in their study phase.

9. COVD-19 effected my educational progress 75 minbsprépensonses
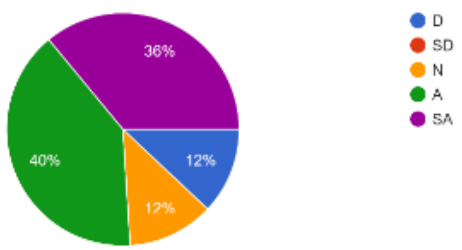

Fig. 9. COVID-19 effected my education progress.

The above figure shows that (40\%) of twenty-five students agreed that Covid-19 affected their educational success, with the remaining students $(36 \%)$ strongly agreeing. Only (12\%) of those polled were neutral, while the remaining (12\%) disagreed. As a result, the findings will be summarized as follows: In this section, the majority of students are impacted by their educational progress, and this includes the research process in general, as well as online learning. This question section aims to examine students' perceptions of public education.

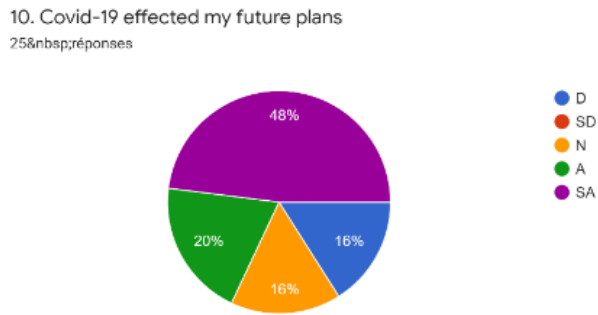

Fig 10. COVID-19 effected my future plans.

The graph above indicates that (48\%) of students strongly agreed that Covid-19 affected their plans, while the remaining students $(20 \%)$ agreed. (16\%) of those interviewed said they were neutral, while another (16\%) said they disagreed. As a result, the results will be summarized as follows: Most students believe that Covid-19 has affected their plans. It is related to the effects of their research process, but we can tell that most students are concerned about their plans after graduation.

\section{Discussion}

The preceding segment was concerned with collecting data from the students' and teachers' questionnaires, which aimed to investigate EFL master two students' Impact of Covid-19 on the Research Process. The preceding section then presented an overview and discussion of the research tools' findings. The results show that students had serious difficulties writing their study papers during the COVID-19 pandemic. Furthermore, it was discovered that these learners' difficulties are caused by a variety of factors, including students' lack of information about these aspects, their inability to find solutions in such a short period even though their supervisors are assisting them, and the majority of students allowing the COVID-19 to affect their mood while writing their articles. As a result, students often complain that they do not 
receive enough help from their teachers. The preceding section also demonstrated that students have some limitations in their writing process and that some supervisors place high standards on their students.

\section{Conclusion}

The study of The Impact of Covid-19 on Research Process Case of Study on Master-2 students at the University of Mohammed Seddik Ben Yahia during the Covid-19 pandemic reveals students' preferences for writing their research papers because it provides them with many limitations and difficulties in writing their dissertation, as well as different perspectives from students on their supervisors, and students engaging with their study materials in the comfort and flexibility of space and time. There was a significant disruption in providing the necessary environment to conduct an experimental study, which forced the researchers to use different methodologies. The study indicates that online technology or social media during the Covid-19 pandemic is not that helpful for communication with the supervisors, especially for the majority of the students. This finding is based on students' mood, self-efficacy, feeling unmotivated, and students' behaviour regarding the covid-19 pandemic. The study affirms that Covid-19 has an impact on both students' research process and plans. Furthermore, the research demonstrates a similar perception of being taught as achieved by physical classroom instruction, as students view online meetings as equivalent to face-to-face meetings. As a result, appropriate steps should be taken to improve the needs of the students to assist with improved outcomes in their research papers and the students' emotions in writing their research papers during the pandemic.

\section{References}

1. F. Nadirah Farah. 'Don't Forget About Graduate Students', THE CHRONICAL OF HIGHER EDUCATION, (2020) https://www.chronicle.com/article/dont-forget-aboutgraduate-students/

2. H. Susan. 'Business as unusual': How COVID-19 brought forward the future of work, (2020). https://news.un.org/en/story/2020/05/1064802

3. G. Vijay., \& S. Anup 'A Post-Pandemic Strategy for U.S Higher Ed' (2020).

4. Walt, Stephen M. "The Global Order After COVID-19." Paper, Institut für Sicherheitspolitik, (2020). https://www.belfercenter.org/publication/global-order-aftercovid-19

5. Nunan, D. (1992). Research methods in language learning. Cambridge: CUP.

6. Wolkewitz, M. and Puljak, L. (2020). Methodological challenges of analysing COVID19 data during the pandemic. BMC Medical Research Methodology, 20(1)

7. Bogle, David. 'How Will Covid-19 affect research collaboration?''(2020) https://www.universityworldnews.com/post.php?story=2020090413393595

8. Korbel, J.O., Stegle, O. Effects of the COVID-19 pandemic on life scientists. Genome Biol 21, 113 (2020). https://doi.org/10.1186/s13059-020-02031-1

9. Thompson, K. J. (2020). The perils of practicum in the time of COVID-19: A graduate student's perspective. Psychological Trauma: Theory, Research, Practice, and Policy, 12(S1), S151.

10. Islam. H. 'Challenges Facing Distance Education in Light of Corona'. (2020). https://www.aa.com.tr/ar/ 